\title{
Measuring Correlation Analysis on Productivity and Carbon Emissions of Construction Industry in China
}

\author{
Dong Zhai ${ }^{1, a}$, Jiayi $\mathrm{Li}^{2, \mathrm{~b}^{*}}$ and Pengfei $\mathrm{Li}^{2, \mathrm{c}}$ \\ ${ }^{1}$ An-Zhong Building A518, Zijingang Campus, Zhejiang University, Hangzhou, Zhejiang, China \\ ${ }^{2}$ An-Zhong Building A525, Zijingang Campus, Zhejiang University, Hangzhou, Zhejiang, China \\ a0012078@zju.edu.cn, bhongkongzhijia@163.com, '259211530@qq.com \\ *The corresponding author
}

\begin{abstract}
Keyword: The construction industry; Carbon emissions; Productivity; Environmental Kuznets Curve; Tapio decoupling model
\end{abstract}

\begin{abstract}
The face of the current global climate warming background, the world has put forward their own energy-saving emission reduction targets. This paper studied the relationship between carbon emissions and productivity of the construction industry in long-term and short-term, respectively, by constructing the environment Kuznets model and the Tapio decoupled elastic model. The research results show that the carbon emissions and productivity of China's construction industry showed the inverted "N-type" curve relationship in the long-term, appeared the recombination effect proposed by Bruyn and Opschoor. The Inverted "N-type" relationship between the characteristics of instability, determines the impact of external factors on the relationship between the two in a certain period of time have a significant impact. And, in the short-term, the relationship between the carbon emissions and productivity of construction industry was greatly affected by the policy and the external economic environment. The implementation of national policies and the explosive construction of real estate and other construction industries will increase carbon emissions in the short term increase.
\end{abstract}

\section{Introduction}

The leading criminal for the global warming is the huge emission of greenhouse gases such as carbon dioxide which is produced by the burning of fossil fuels. In 2009, China made policy requirement on carbon emission, and in the year 2020, China needs to cut down $40 \%$ to $50 \%$ carbon emission on the base of 2005 [1]. Construction industry is the pillar industry of national economy, and its severe dependence on capital and labor input, the extensive growth model, will bring tremendous destroy to resources and environment, it will especially produce a lot of wastes and gas emission. A report made by the China Industry Research Network in July, 2014 showed that in the total amount of carbon emission that the emission of construction industry is up to $50 \%$, the proportion of which is far more than other industries. In recent years, the labor resource is in shortage in Chinese construction industry, with the cost of labor is rising up higher, the mechanization of the construction industry emancipates the labor in a higher degree and improves the project quality as well as labor capacity.

By the technology innovation, the development mode transfer from extensive to refinement, scale and industrialization, the large-scale using of precast structures, assembling construction and steel structures provides the theoretical basis and technology support for the increase of construction productivity. Based on the above, whether the construction carbon emissions could decrease or increase to a more severe degree with the development of scale produce mode, and in order to achieve the goal that this country cut down the carbon emissions in the coming years, whether the construction produce mode formed by the concept of increasing productivity could decrease the carbon emissions, these are the problems that this paper aim to discuss and solve. Based on the example study and results, this paper aims to make further data basis and reasonable suggestions in making cut-down carbon emissions policies and strategies for the construction all 
over the country, and eventually achieve the predetermined goal of cut-down construction carbon emissions for the country.

\section{Literature References}

Existing carbon emissions related research mainly involves carbon emissions, factors that affected carbon emissions, carbon emissions and carbon emissions reduction measures. Carbon emissions from various sectors of the industry from the initial expansion to the transportation industry, construction and other fields; The main factors affecting carbon emissions included economic growth, population factors, industrial structure, energy structure and efficient; The methods of carbon emission measurement were diversified, but the standard of measurement method and calculation coefficient was not uniform, which leaded to the inconsistent calculation result. The countermeasures of carbon emission reduction included actively developing clean energy and developing low carbon technology. However, few studies had examined the correlation between carbon emissions from the construction industry and the productivity of the construction industry. Most of the studies had focused on the construction industry, energy intensity, energy consumption, and so on. Ons and energy consumption in the construction industry in Ireland, and the results showed that about $75 \%$ of carbon emissions in the region came from construction activities. Zhang Tao, a new mathematical model to calculated China's provincial and municipal construction of carbon emissions, the results showed that the building life cycle carbon dioxide emissions were increasing year by year. Shenjun Qi and Yunbo Zhang [2] calculated the carbon emissions of China's construction industry from 1995 to 2009 based on the input-output analysis method, and analyzed the impact factors of direct and indirect carbon emissions using Kaya identity method. Shouhong Xie Based on the industry factorization method, it was important to analyze the impact of various industries on China's total carbon emission and then got the carbon emission of construction industry to play a leading role in reducing the overall carbon emission intensity of China [3]. In terms of carbon emission reduction, carbon footprint analysis was used to analyze the carbon footprint of building life cycle, and also to consider the impact of individual greenhouse gas emissions, from a deeper level analysis of carbon emissions and carbon emission reduction plan.

At present, Kuznets curve is mainly used to measure the relationship between economy and environment, as well as economic and social problems and the relationship between the legal. On the economic and environmental aspects of the study, Kuznets curve further development, resulting in environmental Kuznets curve hypothesis [4]. Holzz-Eakin and Selden analyzed the marginal data on carbon dioxide emissions and local income per capita for countries around the world, and found that the marginal consumption of carbon dioxide declined with economic growth and the 1986 per capita income (US \$ 35,428) "U-shaped" curve of the inflection point [5]. Martinez-Zarzoso and Bengochea-Morancho tested the relationship between economic development and carbon emissions in 22 OECD countries based on a mixed-group mean estimation (PMGE) method. The results showed that there was an environmental library between the two Zenets curve. Widely used to build decoupling indicators of the main economic and development organizations (OECD) and Tapio decoupling indicator construction mode. Based on the basic idea of decoupling and re-hooking in Tapio decoupling, this paper analyzed the decoupling relationship between economic growth and energy consumption in China, and obtained the relationship between economic development and energy consumption in China in the 1980's. Consumption in the weak decoupling relationship, which in 2002 and 2003, both the expansion of the hook re-hook situation. J.W Peng and Huang X.J. studied the decoupling relationship between China's carbon emissions and economic development from two spheres of time and space [6]. From 1980 to 2000 and 2005 to 2008, China's economic growth and carbon emissions were weakly decoupled.

\section{Methodology}

Energy used in the construction industry mainly contains coal, oil, natural gas and electricity. The coal, oil, natural gas was considered to calculate the direct carbon emissions [7]. It needs to 
note that the electricity was considered when calculating the indirect carbon emissions for it was mainly applied in the upstream industry. According to the discharge coefficient method:

Total carbon emissions $=\sum_{\mathrm{i}=1}^{4}$ Consumption of energy $\mathrm{i} \times$ Emission factor of energy $\mathrm{i}$

The letter "i" is the type of the energy. The Emission factor of the coal, petroleum and natural gas are $0.733 \mathrm{~kg} / \mathrm{kg}, 0.588 \mathrm{~kg} / \mathrm{kg}, 0.423 \mathrm{~kg} / \mathrm{m} 3$, respectively.

Based on the direct carbon emissions, the indirect carbon emission could be calculated by the Input-output method:

$$
B_{j}=\sum_{j}\left(\frac{A_{j}}{X_{j}}\right) \cdot\left(X \cdot y_{j}\right)
$$

Where $X_{j}$ is the output of the Industry $j, X$ is the output of the construction industry, $Y_{j}$ is the complete consumption coefficients of the construction industry on the Industry $j,\left(A_{j} / X_{j}\right)$ is the direct carbon emissions of Industry $\mathrm{j}$ at a unit output[8]. $\left(\mathrm{X} \cdot \mathrm{y}_{\mathrm{j}}\right)$ is the amount of output drive of the construction industry on the Industry $\mathrm{j}$.

Library Kuznets (EKC) Model. The Library Kuznets model was applied to study the relationship between the carbon emissions and the production in construction industry in the current study[9]. The results were analyzed with a software Eviews 6.0. The model was set as:

$$
\ln C=\alpha_{0}+\alpha_{1} \ln R+\alpha_{2}(\operatorname{lnR})^{2}+\alpha_{3}(\operatorname{lnR})^{3}+\varepsilon
$$

The conditions required for the Library Kuznets model are $\alpha_{1}>0, \alpha_{2}<0, \alpha_{3}=0$, where the turning point could be calculated as $\mathrm{R}=\mathrm{e}^{-\frac{\alpha_{1}}{\alpha_{2}}}$. It needs to note that not all the data are suitable for the Library Kuznets hypothesis.

Tapio Decoupling Model. Tapio decoupling model was applied to decompose the decoupling elastic between the carbon emissions and the production in construction industry in the current study [10], and the model was proposed as:

(1) The elastic between the carbon emissions and the energy consumption in construction industry;

(2) The elastic between the energy consumption and the production in construction industry;

$$
\mathrm{E}_{(\mathrm{E}, \mathrm{P})}=\frac{\% \Delta \mathrm{E}}{\% \Delta \mathrm{P}}
$$

$$
\mathrm{E}_{(\mathrm{C}, \mathrm{E})}=\frac{\% \Delta \mathrm{C}}{\% \Delta \mathrm{E}}
$$

$$
\mathrm{E}_{(\mathrm{C}, \mathrm{P})}=\frac{\% \Delta \mathrm{C}}{\% \Delta \mathrm{P}}
$$

Where $\mathrm{E}$ is the amount of the energy consumption, $\mathrm{E}(\mathrm{E}, \mathrm{P})$ is the production elastic of the energy consumption, which is related to the energy structure and the efficiency. $E(C, E)$ is the energy consumption elastic of the carbon emissions, which is related to the energy consumption structure and the use of technology. $\mathrm{E}(\mathrm{C}, \mathrm{P})$ is the production elastic of the carbon emissions in construction industry.

\section{Data Description and Analysis}

The data of the current study comes from the China statistical yearbook, where the energy calculated contained coal, oil and natural gas. The period ranged from 1992 to 2012 [11]. Since the energy was computed as coal, coke, crude oil, gasoline, kerosene, diesel oil, fuel oil, natural gas and electricity from 1995, the current study only calculated the indirect carbon emissions of construction industry of the year 1999, 2002, 2005, 2007, 2010 and 2011. According to the result, the direct carbon emissions keep increasing on the whole from 1992 to 2012. Before 1998, the carbon emissions keep stable, or even decrease slightly. However, it keeps increasing after 1998, except in the year 2008 and 2011. Besides, the consumption of the coal and natural gas keep stable from 1992 to 2012, but the consumption of the oil increased from 395.6 Million tons in 1992 to 2699.13 Million tons in 2012. This is because more and more construction machineries are applied 
on the construction industry, and these machineries are larger and larger. More and more prefabricated structures, assembled type buildings, steel structures were constructed. Therefore, the consumption of the oil is increasing significantly.

For the data of the indirect carbon emissions in construction industry is not large enough, the relationship between the carbon emissions and the production in construction industry will be analysis with direct carbon emissions. China statistical abstract gave the data of the added value and the number of employees at the end of each year in construction industry from 1992 to 2012. According to which, the production in construction industry can be calculated. It can be seen that the production in construction industry keep increasing from 1992 to 2012, and also the increasing rate is larger and larger. About which, the application of construction machineries contribute a lot.

\section{Empirical Analysis Result}

The Long-Term Fluctuations Research Result. The result analysis on correlative study on carbon emission and productivity in Chinese construction industry. ADF stability inspection is made on two time series groups, the result shows that the first, second and third series of the productivity and the carbon emission in China construction industry are unstable, however, the difference of the first order is stable, so the chosen series is the whole single first series. ADF stability inspection illustrates that all variables are der bias unstable series, in order to inspect that if the variables have long-term stable relation, Johansen cointegration inspection have to be done on modals. The result shows in Table 1.

Table 1 Johansen cointegration inspection

\begin{tabular}{ccccc}
\hline Original Hypothesis & eigenvalue & Trace Statistic & 5\% significance & P value \\
\hline None & 0.899477 & 127.2398 & 40.17493 & 0.0000 \\
At most $1 *$ & 0.847872 & 76.69768 & 24.27596 & 0.0000 \\
At most $2 *$ & 0.746085 & 35.27096 & 12.32090 & 0.0000 \\
At most $3 *$ & 0.207426 & 5.114318 & 4.129906 & 0.0282 \\
\hline
\end{tabular}

Johansen cointegration inspection result refuses original hypothesis, which shows the time series is cointegrated, namely the carbon emission and productivity in China construction industry have long-term stable relation, the regression analysis on this modal utilizing least square method. Using Eviews6.0 software, we made Kuznets inspection, the regression result is:

$\ln C=4.059160-2.760876 \times \operatorname{lnR}+1.142038 \times(\operatorname{lnR})^{2}-0.120462 \times(\operatorname{lnR})^{3}$

The $\mathrm{Q}$ inspection shows that when the significance level is $5 \%$, autocorrelation efficient is relatively small, that is there is no correlativity. In LM inspection, when $p=1$ and 2 , the $P$ value is 0.0495 and 0.1445 respectively, both are big, which shows that residual has no serial correlation. Root of unity inspection is done on the residual series, when the confidence level is $1 \%$, the residual series has no root of unity, namely the residual is stable, and regression equation is not pseudo-regression. According to the analysis above we can conclude again that there is a long-term stable relationship between China carbon emission and productivity in carbon industry.

According to the data analysis we get the result as shown in Fig. 1, carbon emission and productivity in China construction industry has cubic curve relation which is like an inverted "N", before the productivity reaches 5210 per person (as shown in Fig. 1 the productivity value is 1.6506), carbon emission decreases as the productivity increases, after this turning point, the carbon emission increases as the productivity increases. After the productivity reaches 109,840 per person (as shown in Fig. 1 the productivity value is 4.6990), the carbon emission again decreases as the productivity increases, which stands for the China construction industry entering into a fine developing phrase gradually, the carbon emission gets eased. 


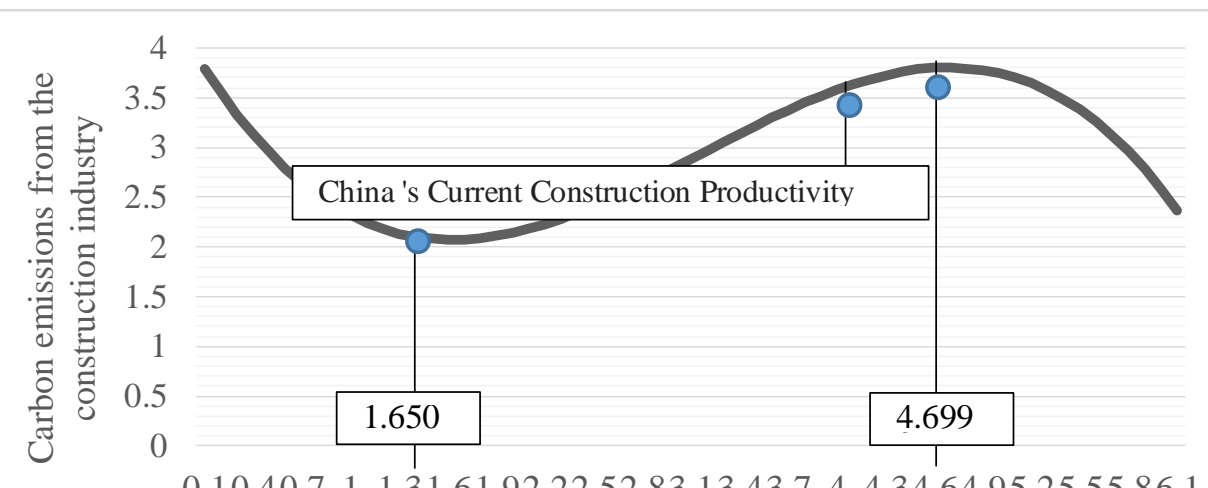

Productivity of construction

Figure 1. The fitting result of carbon emission and productivity in China construction industry

Data analysis shows that current carbon emission and the productivity in China construction industry is forward direction relation. The productivity is 57,290 and 62.300 yuan per person in 2011 and 2012 respectively (as shown in Fig. 1 Ln productivity value is 4.05 and 4.13), the productivity increases rapidly, but the carbon emission increases also. Conjecturing from the curve, the developing trend will last for a certain time. When analyzing from long run, carbon emission and productivity in China construction industry is like an inverted " $\mathrm{N}$ ", there existing recombination effect which is put forward by Bruyn and Opschoor. Recombination hypothesis thinks that the inverted "U" relation between environmental changes and economy development in Kuznets curve applies only to short and medium term, if influenced by policy and economic development factors in medium and long term, the relation between environment and economy will not separate for a long time. However, when the economy develops to a certain phrase, the two will recombine. Namely, the increases of productivity will bring the increase of carbon emission, but when the productivity increases to a certain level, carbon emission will get eased, so as to decrease the pressure on environment which maybe lead by the progress of techniques and the transformation of production modes in construction industry. So seeing from the long run, carbon emission and the productivity in China construction industry is inverted "N" relation rather than inverted " $U$ ".

The Short-Term Fluctuations Research Result. According to the calculation of energy consumption, carbon emission and production firm the year 1992 to 2012, and based on Tapio Decoupling Modal, the correlative decoupling index used to calculate carbon emission and productivity in construction industry is shown in Table 2:

According to Decoupling Theory, strong decoupling state is the most ideal state to reach the goal of low-carbon development, strong-negative state vice versa. Seeing from Table 2, during 1992-2012, among which there are 8 years are strong decoupling state, 4 years' carbon emission productivity elasticity broke through 1.0 which stay in the expansionary negative decoupling state, while the rest 9 years stay in the weak decoupling state, especially in 2009 and 2010, there are big fluctuations. From 2003 to 2012, during the ten years, except 2008 and 2011 are strong decoupling, the other years stay in weak decoupling and expansionary negative decoupling state, when compared with the former ten years, there is a stronger relevance between productivity and carbon emission in construction industry.

Carbon emission and the productivity in China construction industry grew rapidly in the early 21century, which has close relationship with the booming Chinese real estate. Because at that time there are no many restricted papers on carbon emission in construction industry, the improvement of productivity which brought by the large-scale real estate construction wasn't based on reasonable planning, but the desire to construct the real estate fast. Besides, we can see that around 2008 the carbon emission in construction industry decreased by $23.96 \%$, the reason probably is that the construction industry was influenced by global financial crisis and the depressive policy put forward by the Chinese government, the construction projects decreased substantially nationwide, at the same time, China held 2008 Beijing Olympic Games, tin order to improve the environment, 
China put forward a series of restricted policies on carbon emission, policy factor plays a vital role. However, in 2009 and 2010, there was an obvious fluctuation of decoupling relation between carbon emission and productivity in construction industry, especially in 2010 the decoupling elasticity value reached up to 5.982. This fluctuation maybe caused by the Chinese government who had to cope with the financial crisis broke out in 2008, to rapidly implement " 4 trillion investment" market saving plan thus there were numerous projects boot fast. In a short period of time, numerous construction projects started constructing which made the carbon emission and productivity relation in construction industry exceptional.

Table 2. Correlative decoupling index result of carbon emission and productivity in construction industry, 1992-2012

\begin{tabular}{llcl}
\hline year & Decoupling state & year & Decoupling state \\
\hline 1992 & Weak decoupling & 2004 & Weak decoupling \\
1993 & Strong decoupling & 2005 & Expandable negative decoupling \\
1994 & Strong decoupling & 2006 & Weak decoupling \\
1995 & Strong decoupling & 2007 & Weak decoupling \\
1996 & Expandable negative decoupling & 2008 & Strong decoupling \\
1997 & Strong decoupling & 2009 & Expandable negative decoupling \\
1998 & Strong decoupling & 2010 & Expandable negative decoupling \\
2001 & Strong decoupling & 2011 & Strong decoupling \\
2002 & Strong negative decoupling & 2012 & Weak decoupling \\
2003 & Weak decoupling & & \\
\hline
\end{tabular}

\section{Conclusion}

Through the above research, we can draw the following conclusions:

(1)The research results show that the carbon emissions and productivity of China's construction industry showed the inverted "N-type" curve relationship in the long-term, appeared the recombination effect proposed by Bruyn and Opschoor. That is to say, the increase of the productivity will result in the increase of the carbon emissions of the construction industry, however, the latter would be relieved when the former reach a certain level and further reduce the pressure on the environment, which may be caused by the development of the construction technology and the transform of the product mode.

(2)The current construction productivity of China and the carbon emissions have a positive relationship; it would take a while for the development trend in the short-term, it was demonstrated by the result. of the construction carbon emissions and the productivity, which were calculated based on the Tapio decoupled model, that the relationship between the carbon emissions and productivity of construction industry was greatly affected by the policy and the external economic environment, for instance, the factor of global financial crisis, the "four trillions investment" saving market plan made by Chinese government, the real estate suppression policy and so on, would lead the decoupled relationship between the carbon emissions and productivity of construction industry to abnormal. In general, with the gradually advance of construction industry, the construction product mode would transfer from extensive to refinement, scale and industrialization. In the future, the construction carbon emissions may increase as a result of the large-scale using of the construction product mechanics and the transportation mechanics, but when the construction industrialization reaches a certain level, the carbon emissions would decrease as the increase of the construction productivity.

\section{References}

[1] T.X. Zhang, Y.Y. Zhou and P. Lu: Journal of Hunan University of Technology, Vol: 25 (2011) No.1, p.77-80(In Chinese). 
[2] S.J. Qi and Y.B, Zhang: Soft Science, Vol: 27(2013) No.6, p.39-43(In Chinese).

[3] S.H. Xie, L.X. Wang and Z.L. Shao: Arid Land Geography, Vol: 37 (2014) No.4, p.720-730(In Chinese).

[4] Z.I. Martinez and M.A. Bengochea: Economics Letters, Vol: 82 (2004) No.1, p.121-126.

[5] S.M. Bruyn and J.B. Opschoor: Ecological Economics, Vol: 20(1997) No.3, p.255-268.

[6] K.F. Sun and S. Chen: Building Carbon Measurement Methodology (China Building Industry Press 2014), p.106.

[7] N.C. Onat, M. Kucukvar, and O. Tatari: Building and Environment, Vol: 72(2014) No.2 p. 53-62.

[8] S. Śmiech, and M. Papież: Energy Policy, Vol. 71(2014).No.7 p. 118-129.

[9] H.J. Liu, Q.Y. Yan and R.Y. Sun: China Science and Technology Forum: Vol. 68(2011) No.4. p. 108-113(In Chinese).

[10] Tapio: P.Transport Policy, Vol. 12(2005) No.2 p. 137-151.

[11] Information on http://www. stats.gov.cn 